\title{
OS ESTUDOS LITERÁRIOS BRASILEIROS NOS ANOS 1970 E O LUGAR DA TEORIA NO TRABALHO DE LUiz COSTA Lima
}

\section{BRAZILIAN LITERARY STUDIES IN THE 1970's AND THE Place of Theory in Luiz Costa Lima's Work}

\author{
Jefferson Mello
}

Resumo: Neste artigo, busco analisar e discutir a presença das teorias estruturalistas no trabalho de Luiz Costa Lima, na década de 1970, apontando, também, como elas se conectam às questões institucionais e políticas do período. Tento demonstrar que, a partir do seu livro de 1973, Estruturalismo e teoria da literatura, e de uma série de artigos publicados em suplementos literários, o autor articula as discussões propriamente teóricas àquelas vinculadas tanto ao subcampo da crítica literária quanto a uma interpretação do contexto político brasileiro.

Palavras-chave: teorias estruturalistas; Luiz Costa Lima; estudos literários.

Abstract: The goal of this article is to analyze the presence of the structuralist theories in the work of Luiz Costa Lima in the 1970's. I also discuss how they connect to political and institutional issues of that period. I aim to demonstrate that through his book of 1973 Estruturalismo e teoria da literatura [Structuralism and Theory of Literature] - and a series of articles published in newspapers literary supplements, the author links the discussions and polemics about both the theory to both the literary criticism field in Brazil and to the Brazilian political context.

Keywords: Structuralist Theories; Luiz Costa Lima; Literary Studies.

${ }^{1}$ Professor Associado da Escola de Artes, Ciências e Humanidades da USP: <jefferson@ usp.br>. 
As teorias estruturalistas² tiveram acolhida no Brasil, nos anos 1970, junto a três professores do curso de Pós-graduação em Literatura Brasileira da Pontifícia Universidade Católica do Rio de Janeiro (PUC-Rio): Silviano Santiago, Luiz Costa Lima e Affonso Romano de Sant'Anna. A partir delas, eles produziram ensaios e livros e orientaram um bom número de teses de mestrado, formando professores e pesquisadores, muitos dos quais se tornaram docentes das novas universidades públicas que surgiram no período. $\mathrm{O}$ objetivo deste ensaio, que é parte de uma pesquisa mais ampla, ${ }^{3}$ é discutir a forma que as teorias estruturalistas adquiriram na obra de Luiz Costa Lima e de que modo elas se conectavam às questões institucionais, teóricas e políticas do período. O meu ponto de partida são artigos, publicados em jornais e periódicos, nos anos 1970, em torno do que se convencionou chamar de a "polêmica estruturalista" no Brasil. Eles permitem situar os debates, assim como introduzir alguns dos posicionamentos de Costa Lima. Em um segundo momento, analiso o seu livro Estruturalismo e teoria da literatura, de 1973. Trato de demonstrar que a obra mira tanto as discussões teóricas do período quanto a cena intelectual, mais especificamente, a situação dos estudos literários no Brasil, bastante marcadas, ainda, pela endogenia das universidades mais consolidadas, a saber, a Universidade Federal do Rio de Janeiro (UFRJ) e a Universidade de São Paulo (USP). Argumento, por fim, que se o esforço teórico de Costa Lima é em direção a uma maior autonomia da área dos estudos literários, ele não deixa de conter, também, uma crítica de cunho institucional e político, em confronto com as posições e os agentes dominantes.

Uma das críticas ao estruturalismo mais famosas é a de Roberto Schwarz (2008, pp. 112-114), que em 1976 escreveu com muita ironia um texto chamado “19 princípios para a crítica literária”. Entre eles, destaco

\footnotetext{
${ }^{2}$ Certamente, há diferenças entre o estruturalismo e o pós-estruturalismo, no entanto, há mais similaridades, que vão desde as origens francesas e/ou francófonas até a concepção de linguagem e de sujeito. Neste ensaio, utilizarei o nome teorias estruturalistas para me referir a ambos, até porque importa menos a fidelidade a um movimento ou corrente teórica do que os usos que os críticos e teóricos brasileiros fizeram das ideias e de seus autores de referência.

3 Trata-se da pesquisa "Os estudos literários brasileiros nos anos de 1970 e a recepção do estruturalismo/pós-estruturalismo: o caso da PUC-Rio", que contou com financiamento da Fapesp, no primeiro semestre de 2019 (processo n. 2018/23180-8).
}

Remate de Males, Campinas-SP, v.40, n.2, pp. 697-722, jul./dez. 2020 - 698 
os seguintes: "2. Citar em alemão os livros lidos em francês, em francês os espanhóis, e nos dois casos fora de contexto"; 5. "Não esqueça: o marxismo é um reducionismo, e está superado pelo estruturalismo, pela fenomenologia, pela estilística, pela nova crítica americana, pelo formalismo russo, pela crítica estética, pela linguística e pela filosofia das formas simbólicas"; "14. Publique longos resumos de livros sem importância, convença o editor a traduzi-los e o leitor a lê-los. Há quase 700 mil universitários no país"; "15. Um doutoramento vale ouro"; "16. O semantema glúteo em linguística moderna tende à polissemia"; "18. Os livros editados pela Universidade de Indiana e importados pela Livraria Pioneira são importantíssimos. Se pelo contrário você é de formação francesa, não deixe de aplicar o método de Chomsky e Propp. O resultado não se fará esperar"; "19. Muito cuidado com o óbvio. O mais seguro é documentá-lo sempre estatisticamente! Use um gráfico se houver espaço".

Nos trechos selecionados, o ataque de Schwarz visa, sobretudo, 1) aos usos inadequados e fetichistas das ideias e modas teóricas estrangeiras, nem sempre compreendidas a fundo, o que significa um deslumbramento provinciano inconsequente e oportunista; 2) ao aspecto despolitizado e pretensamente científico do estruturalismo, cuja base, segundo ele, é a linguística; e 3) à articulação entre as novidades estrangeiras e o pragmatismo acadêmico, o que indica, outra vez, oportunismo e adequação ao livre-comércio das ideias, presentes, no caso, no ambiente universitário. Assim, ao lado do problema do lugar das ideias e do da dependência (econômica e cultural), que estão na base do pensamento de Schwarz - pelo menos desde a sua frequentação do célebre Grupo do Capital, ainda no início dos anos $1960^{4}$-, suas preocupações, nos anos 1970, concernem, igualmente, à formação de uma crítica/teoria brasileira na universidade. Sintoma da expansão desta ("Há quase 700 mil universitários no país") e, consequentemente, de perspectivas de trabalho nela, a crítica de Schwarz se torna bifronte: ele abrange, ao mesmo tempo, o fora (o espaço social) e o dentro, isto é, a instituição universitária, os pares, as teorias propriamente ditas, o estatuto do pesquisador; por

${ }_{4}$ Para se ter um apanhado das ideias do grupo, ver, do próprio Schwarz (1999), "Um seminário de Marx". 
exemplo: ao escrever que "um doutoramento vale ouro", o autor sinaliza que um título de doutor garante uma carreira profissional. ${ }^{5}$

Se nos "19 princípios..." Schwarz apenas sugere a relação da importação de ideias estruturalistas com a abertura para a carreira docente, o diplomata e crítico literário José Guilherme Merquior, em "O estruturalismo dos pobres”, publicado no Jornal do Brasil em 27 de janeiro de 1974, faz dessa ideia o seu principal argumento. Entre outras coisas, ele afirma que "o estruturalismo é o paraíso do Método" (MERQUIOR, 1974, p. 5) e que

[...] a nova crítica [...] se alimenta do mito do modelo do mecanicamente aplicável. Pós-graduandos incrivelmente ignaros, outrora incapazes, por simples analfabetismo, de empreender a interpretação de obras pejadas de referências culturais, agora se entregam sem nenhuma inibição à volúpia de aplicar a torto e a direito modelos "científicos" de análise (MERQUIOR, 1974, p. 5).

Também, segundo ele, “as universidades ‘brotam’ agora (numa expansão demasiado rápida para ser levada a sério), e os ignorantes se diplomam e se doutoram às centenas" (MERQUIOR, 1974, p. 5). O que cria uma articulação, para ele perversa, entre a teoria facilmente assimilável e aplicável e a expansão universitária. Segundo Merquior,

[...] não é por acaso que o ator ou espectador por excelência do festival estruturalista é o aluno ou ex-aluno da universidade massificada; da

\footnotetext{
${ }^{5}$ De acordo com Luiz Cunha (1988, pp. 86-87), que estudou o período, “a mudança do regime político em abril de 1964 não fez retroagir a crescente procura de ensino superior. Ao contrário, a fez avançar. O crescimento da população urbana, a industrialização e a monopolização, gerando aumento das camadas médias, em termos absolutos; a redefinição do papel da mulher como trabalhadora no âmbito extradoméstico; a elevação dos cargos nas burocracias públicas e privadas, foram processos que seguiram seu curso após o golpe. Ademais, eles se intensificaram pela política econômica adotada”. Para suprir a demanda estudantil com mão de obra local, registra-se, desde o final dos anos 1960, o surgimento dos Cursos de Pós-Graduação (mestrado/doutorado), no modelo americano, sendo que o primeiro deles é na área de educação, na PUC-Rio. Por um lado, esses cursos, que acompanharam a extinção da cátedra, acabaram contribuindo para o aumento de contratações de docentes com dedicação exclusiva nas universidades, com incremento salarial para estes, e para um maior nível de especialização, por conta, também, de uma nova disposição que o docente assumia, menos diletante e mais engajada institucionalmente. Por outro lado, nesse mesmo pacote de mudanças, encampado pelo governo militar, reforçava-se o combate ao comunismo e a relação da universidade com o mundo empresarial, seguindo diretrizes estadunidenses, que inspiravam, em boa medida, os nossos generais. Para uma apreensão do surgimento das pós-graduações em literatura no Brasil e de suas linhagens críticas, ver o estudo de Rachel Esteves Lima (1997).
} 
universidade que, desejando-se socialmente antielitista, por fidelidade ao imperativo da democratização do ensino, vem destruindo, consciente ou inconscientemente, o outro elitismo da universidade tradicional - o seu legítimo aristocratismo intelectual (MERQUIOR, 1974, p. 5).

Em primeiro lugar, a ideia de que há no Brasil um "festival estruturalista" remete aos festivais de música do período e cria uma associação entre estruturalismo, cultura de massa e juventude rebelde. Em segundo lugar, por meio de uma posição que é também de classe (o estruturalismo é "dos pobres"), o autor sugere o vínculo entre o aluno da universidade de massas que adota o estruturalismo e o fim da universidade tradicional, de elite. Além disso, alerta para o fato de a vida intelectual do país estar tomada pela universidade, e, mais grave ainda, de acordo com ele, por um modelo desta, mais democrático.

Por um lado, as críticas de Merquior e Schwarz, feitas à época em que ambos viviam na França, onde fizeram seus doutorados, ${ }^{6}$ replicam disputas francesas entre a velha Sorbonne e as novas instituições, ${ }^{7}$ ou, ainda, entre fenomenologia e estruturalismo, explication du texte e semiótica, erudição e ciência. Por outro lado, vistas a partir da realidade brasileira, que também acompanhavam de perto, as posições de ambos revelam uma outra contenda e, mais do que isso, certa preocupação, por parte de um grupo de intelectuais e escritores em choque com uma nova prática letrada. Escreve Merquior (1974, p. 5) que "todos os semblantes do terror estruturalista possuem o mesmo pressuposto - a rarefação do espírito crítico cansado e estimulado pelo abaixamento intelectual da universidade, no preciso instante em que esta se lança a abranger ou incorporar a quase totalidade do trabalho literário e erudito".

Assim, é possível relacionar o problema do estruturalismo em si, como sistema de pensamento, às transformações institucionais e sociais em curso no período, no instante em que a ampliação do sistema de ensino superior e o surgimento da nova pós-graduação são postos em marcha no Brasil. Em síntese, para Merquior, o estruturalismo não é apenas um método entre outros, mas um método que, no Brasil, é apropriado indevidamente e por sujeitos desclassificados culturalmente, o que vem a minar uma (suposta) estabilidade do nosso sistema literário.

\footnotetext{
${ }^{6}$ Ambos se doutoraram na Sorbonne "pós-maio", sob a orientação de Raymond Cantel; Merquior terminou o seu doutorado em 1972, Schwarz, em 1976.

7 Entre elas Vincennes, quartel general estruturalista. Para uma história dessa instituição, ver Soulié (2012).
} 
Com o mesmo espírito de disputa entre consagrados e recémchegados, o poema "Exorcismo", de Carlos Drummond de Andrade, publicado em 12 abril de 1975, no Jornal do Brasil, e o artigo de Ledo Ivo, "A morte da literatura brasileira", alguns meses depois, em O Globo, podem ser lidos como reação - mas, no caso, de escritores estabelecidos a essa entrada em campo da teoria da literatura de viés estruturalista. De acordo com o que se lê em ambos os textos, o novo modelo de professor universitário, mais autônomo, protegido pela instituição e munido de saberes recém-chegados de fora, profana o espaço sacrossanto da poesia e da linguagem artística, sobrepondo a este um código que lhe é estranho. Por isso a repetição, no poema de Drummond, a cada estrofe, como se fosse uma ladainha, do verso "Libera nos domine". Vale relembrar a primeira delas, que, como as outras, exibe uma coleção de termos e categorias da linguística e da semiótica, de que o eu poético e seu leitor cúmplice pedem para se verem livres.: "Da leitura sintagmática/ Da leitura paradigmática do enunciado/ Da linguagem fática/ Da fatalidade e da não fatividade da oração principal/ Libera nos domine" (ANDRADE, 1975, p. 5).

Já, no artigo de Ledo Ivo, publicado em 23 de junho de 1975, lê-se, como no texto de Merquior, o vocábulo "terror", articulado então à nova perspectiva teórica em pauta e aos seus supostos lugares de enunciação, que serão confrontados, no caso, pela literatura de verdade que esse poeta de 1945 acaba por evocar como forma de salvação:

[...] terror que mata as letras está na comunicação pedagógica ou para/
pedagógica que considera a teoria mais importante do que a prática. Digamos
sem medo: o carrasco é o teórico ou exegeta que embalsama o texto vivo, o
censor é o professor. Uma cátedra de Teoria Literária exerce sobre a criação
artística atuação semelhante à dos zelosos servidores públicos que veem
antecipadamente as peças de Chico Buarque de Holanda. Em vez de ensinar aos
alunos como devem proceder para criar, o cognominado mestre inocula neles
a ilusão de que a teoria tem mais importância do que um soneto de Baudelaire
ou um conto de Machado de Assis (IVO, 1975, p. 37).

Mesmo sem menções explícitas à teoria estruturalista, é certamente a ela que o autor se refere sob o nome de Teoria Literária, apontando, ainda, os adeptos dela como próximos dos censores - e carrascos! - da ditadura militar, na sua missão de silenciar os voos da imaginação, em uma clara confusão - ou bem pensada estratégia discursiva - da função da universidade, que nunca foi, no Brasil, um espaço para formar escritores, mas sim, professores. No centro da discussão, porém, está tanto a produção 
da literatura quanto o lugar e o sujeito legítimos para falar dela e para refletir sobre ela. O texto termina assim:

[...] se algum jovem quiser ser salvo, e converter-se no escritor profissional ou célebre poeta de amanhã, o discurso intelectual o salvará. Basta-lhe jogar numa cesta de papel o teórico literário recomendado pelo professor (geralmente é uma apostila traduzida do espanhol e vendida a 8 cruzeiros) e abrindo o livro de poemas de Valéry descobrir finalmente e para sempre que a linguagem é a honra dos homens: "Honneur des hommes, SAINT LANGAGE" (IVO, 1975, p. 37).

O pressuposto de Ledo Ivo é o de que a literatura, o poema, já contenha a sua interpretação. Mais ainda, como a palavra divina, ele é eterno e está acima das cifras do mercado. Quem pode explicar os textos literários é o "discurso intelectual", proferido pelo literato, e não pelo "teórico literário". A propósito, o uso do campo semântico religioso - "ser salvo", "converter-se", "SAINT" - aproxima definitivamente literatura e religião, afastando aquela, portanto, da ciência dos novos scholars. De um lado, estão o terror estruturalista e a apostila a preço módico, mercadoria barata e popular, de outro, a santa literatura.

Na base da ideia de terrorismo/terror cultural a que os textos de Merquior e Ivo fazem menção, ecoam, além da referência francesa ao estruturalismo, ${ }^{8}$ um artigo de Alceu Amoroso Lima, de 1964, intitulado "Terrorismo cultural", em que o crítico equipara ao terrorismo o modo como o governo dos militares estava tratando os intelectuais e artistas. Escreve Lima (1964, p. 232):

Quando são demitidos dos seus cargos homens de reputação mundial no plano da educação, como Anísio Teixeira, no plano da sociologia, como Josué de Castro, no plano da economia, como Celso Furtado, simplesmente por pensarem diferente da nova ideologia dominante, estamos no plano do terrorismo cultural.

De modo que a memória desse artigo, trazida à tona por Ivo e Merquior 10 anos depois, faz com que o leitor relacione o estruturalismo à brasileira ao aparelho repressor do Estado.

$\mathrm{Na}$ berlinda de todos esses textos estão, com efeito, os professores estruturalistas da PUC-Rio. Assim, em 1975, Luiz Costa Lima escreve um artigo para o jornal Opinião, em que reage aos que o condenam. O título

\footnotetext{
8 “Terrorismo teórico" é o que, segundo Philippe Forest (1995), dizia-se que os estruturalistas franceses em torno da revista Tel Quel praticavam, ao ler a literatura com as ferramentas da ciência.
}

Remate de Males, Campinas-SP, v.40, n.2, pp. 697-722, jul./dez. 2020 - 703 
do seu texto é "Quem tem medo de teoria”, e o argumento de base é o de que se está criando, pela primeira vez no país, alguma reflexão teórica que tenha como objetivo refletir sobre - e formalizar - o "discurso literário", no caso, um "discurso entre outros". Ao se tomar o "discurso literário", e não a literatura, como objeto, por meio de um conjunto de conceitos oriundos muitas vezes de outras áreas (o que ficará evidente quando tratarei mais adiante da obra teórica de Costa Lima), algumas vozes estabelecidas reagem, primeiramente, em nome da pureza do literário e do acesso direto às obras, que a teoria em excesso não permitiria. Segundo Costa Lima (1975a, p. 24), o literário, mediado pela teoria, deixa de pertencer apenas a poetas e eruditos e, por meio de um vocabulário partilhado pela comunidade científica, passa a ser objeto de exame de quem quiser. Ao insistir na formalização, é, pois, seu objetivo, "mostrar que a linguagem não é propriedade de alguém, nem do autor do poema, nem do leitor que curtiu, nem do intérprete 'não teórico' que nos antecede" (p. 24).

As duas primeiras respostas ao texto de Costa Lima vêm de dois colegas universitários. Um deles, Carlos Nelson Coutinho, da ala marxista do Rio de Janeiro, condena não a teoria, mas sobretudo a que Costa Lima defende, que, segundo Coutinho, se quer asséptica, uma teoria - para usar o vocabulário da época - alienada. O seu limite é a linguagem, e ela não leva em conta que a própria linguagem e a literatura estão subordinadas às transformações sociais. Coutinho (1975, p. 19) defende uma obra de arte que é tanto uma objetivação histórico-social quanto uma forma de "expressar a autoconsciência da humanidade", e não a mera abstração linguística. Em um segundo nível, o seu discurso chama a atenção por, como os outros, se referir à ameaça que essa teoria representa. Escreve ele que ela "tomou de assalto a universidade brasileira, bem como os meios disponíveis para a divulgação da chamada cultura de massa" (p. 19). Mais ao fim do texto, volta a mencionar o monopólio estruturalista, o que justificaria as reações contrárias a ele.

Não cabe aqui julgar o exagero de Coutinho a respeito da existência ou da extensão desse monopólio, ${ }^{9}$ mas refletir sobre como esse medo da presença de uma ciência da linguagem que se quer neutra (pelo menos é

\footnotetext{
9 Ao comentar o grupo da revista Tel Quel, Philippe Forest trata do mesmo superdimensionamento da representatividade das teorias estruturalistas na cena intelectual francesa. Escreve ele: "se nós analisarmos sua importância em termos de geopolítica cultural, Tel Quel não ocupou jamais a posição hegemônica” (FOREST, 1995, p. 301).
} 
assim que ele lê Costa Lima) se conecta a menções sub-reptícias à alienação política da parte do adversário, isto é, de seu investimento em especialista no "campo teórico". Por isso, na conclusão do texto, ao mesmo tempo em que reitera o que já observou Merquior - a saber, a predominância do discurso da universidade sobre o discurso intelectual mais amplo -, ele convoca Costa Lima a ir além da teoria. Assim, posicionando-se como intelectual público, e não como scholar, Coutinho suspeita do projeto de teoria defendido por aquele. ${ }^{10}$

De sua parte, Antonio Carlos de Brito, o Cacaso, que é também professor da PUC-Rio, ecoa em seu artigo preocupações gerais. Na condição também de poeta, é compreensível que, de chofre, dê razão a Drummond e seu poema "Exorcismo". Toma distância do que chama de academia e de instituição universitária; vê aquela como anódina e esta, como o que deve ser transformado por mais participação política. Então, se Coutinho puxa o argumento para o lado da reflexão social, já que atua, também, no campo intelectual em sentido ampliado, Cacaso aposta na política que deveria permear também a universidade. Depois de criticar Costa Lima por este defender o rigor científico em nome, segundo ele, do progresso e se esquecer dos "componentes institucionais" da teoria, Cacaso escreve que a questão da excessiva teorização nos cursos de literatura e nas faculdades de letras constitui "um problema essencialmente pedagógico, de prática institucional, portanto um problema imediatamente político. Neste caso, a reflexão teórica fica acadêmica, sem interesse, se não vier combinada com a reflexão política” (BRITO, 1975, p. 20). Assim, para Cacaso, a universidade, para ser relevante, precisa fazer parte da vida política, fechar-se menos, ouvir mais os alunos. Enquanto Costa Lima vê que a presença da teoria pode ampliar a participação no âmbito acadêmico, tirando-se dos poetas, dos jornalistas e dos universitários representantes do status quo acadêmico o poder de interpretação e julgamento, Cacaso acredita que o isolamento do scholar não permite que se observe a política que subjaz à teoria. Nessa percepção, um encarna a posição do poeta (marginal-)professor, de onde

\footnotetext{
${ }^{10}$ Para Forest (1995, p. 304), o que aterroriza a crítica francesa, a partir das posições dos teóricos de Tel Quel, e que permite fazer uma aproximação com o que acontece no Brasil, nas propostas estruturalistas, principalmente nas de Costa Lima, é o fato de que, para Derrida e Barthes, a obra não reflete mais uma realidade exterior a ela, mas põe em cena o processo de sua própria gênese; "ela nos faz assim penetrar nesse espaço de linguagem que é nosso único horizonte” (FOREST, 1995, p. 304). Como se verá, o espaço da linguagem não é, necessariamente, o único horizonte para Costa Lima.
} 
decorre a sua ojeriza à formalização, que é, para ele, pró status quo; o outro, a do scholar, daí a disposição a formalizar.

Em boa medida, a intervenção de Cacaso é uma espécie de preâmbulo à da poeta e estudante da PUC-Rio, Ana Cristina César, no número seguinte do Opinião. De acordo com Italo Moriconi (2016), que escreveu um depoimento de geração sobre ela, o texto "Os professores contra a parede" apareceu como o arremate da discussão em torno da teoria. Moriconi (2016, p. 780) o interpreta da seguinte forma:

\begin{abstract}
[...] adotando uma perspectiva próxima a Foucault [...], Ana deslocava a própria questão da teoria para a relação da instituição com o saber, retirando-a do campo da relação com um conceito abstrato de conhecimento e, de resto, também de política. A política era colocada no coração da produção e da transmissão do saber. Os conflitos institucionais do saber não podiam ser explicados no terreno da epistemologia.
\end{abstract}

Com efeito, para Ana Cristina César (1975), alunos estariam reclamando, em surdina, das imposições da teoria, tanto da sua dificuldade conceitual, quanto do fato de ela se colocar no lugar da leitura dos textos literários, que é o que os alunos gostariam para as suas carreiras profissionais, já que seriam professores de literatura. Assim, a teoria (outro nome para as teorias estruturalistas), que, de acordo com Costa Lima, está acima das questões ideológicas, funciona, segundo Ana Cristina, como um mecanismo de poder e repressão exercido dentro da universidade, isto é, a teoria, na perspectiva dela, possui um viés ideológico não declarado. Em suas palavras, "é preciso acabar com a ideia de que os debates e as produções de conhecimento se desenvolvem no céu puro da verdade ou da ciência" (CÉSAR, 1975, p. 20). Trata-se, assim, de politizar as teorias, indicando os seus usos repressivos. Entre os usos repressivos, estão estes dois: 1) a relação erótica (e de poder) que se estabelece entre professor e alunos e que tem a teoria como mediadora; professores são descritos por ela como sultões em seus haréns de seguidores cegos; e 2) a imposição de uma teoria, defendida pela instituição, que colocaria os alunos numa posição de aceitação passiva, por causa do seu nível de esoterismo e impenetrabilidade. Haveria, então, para Ana Cristina, um "terrorismo" teórico. Diferentemente de Cacaso, que evita o embate, ela traz à tona o que, segundo ela, está acontecendo na sala de aula. Mas, assim como ele, ela reflete sobre a política institucional e tem a percepção de que a teoria não é condizente com a transformação, desejada por ela, das relações 
professor/aluno. A partir de um relato de inspiração etnográfica, da sala de aula e dos alunos, Ana Cristina escreve que

[...] essa sujeição porém não é simplesmente intelectual mas está inscrita no próprio corpo dos alunos e professores e se expressa na sua postura dentro da sala de aula e diante do próprio trabalho: na ocupação física do espaço escolar, na submissão a um modelo de comportamento ou a uma teoria, na afirmação de uma determinada teoria como a Teoria (CÉSAR, 1975, p. 20).

Ela introduz, assim, uma nova posição no debate, a dos alunos, tornando-se a sua porta-voz e, ao mesmo tempo, ao final do texto, registrando fragmentos de falas e posições deles, isto é, deixando-os falar. Igualmente, em momentos do texto, traz a voz dos poetas revoltados, embora diga que não é esse o caminho da sua discussão com a teoria. Ainda, encarnando uma terceira posição, Ana Cristina busca se colocar como uma interlocutora em potencial dos professores "teóricos". E, o mais curioso, ela se lança nesse debate com as armas, isto é, com os pressupostos do próprio estruturalismo, a partir de autores como Michel Foucault e Louis Althusser, ao mencionar as formas como a "instituição" é ideológica, repressiva, e como ela disciplina e dociliza os corpos.

Em 1973, Foucault é convidado para uma série de cinco conferências na PUC, publicadas depois, em 1974, nos Cadernos PUC, sob o título "A verdade e as formas jurídicas". Essas conferências versam sobre o modo como as sociedades surgidas no século XIX deslocam as formas de controle, da punição propriamente dita ao disciplinamento dos indivíduos por meio de suas instituições que têm a missão de prevenir virtuais delitos. Nesse sentido, para o autor, instituição é algo que serve para domesticar as pulsões. Mais ainda, de acordo com ele, as próprias formas de conhecimento se transformam em instâncias de disciplina, como demonstraria Gilles Deleuze com o seu Anti-Édipo, obra na qual este argumenta que a própria psicanálise, ao institucionalizar o complexo de Édipo, busca controlar os instintos. O que Foucault chama de sous-pouvoir impregna, assim, toda a vida social, com o fito de defender a sociedade dos sujeitos desviantes. No limite, então, a própria teoria estruturalista, que se quer não personalista, pode funcionar como um sous-pouvoir.

Costa Lima não só assiste aos seminários da PUC-Rio como também participa deles na condição de debatedor. Na sua intervenção, o teórico brasileiro afirma que Foucault fetichiza o poder, só vê o poder como algo negativo, algo que ele caracteriza, na sua fala, como hippie e anarquista 
(FOUCAULT, 1994, pp. 641-642)." Ao que Foucault responde que não é bem assim, que, como tentou apontar em sua conferência, o poder penetra instituições e saberes, apesar de, de modo positivo, o poder também estar, eventualmente, na base das relações amorosas. Mas - é preciso lembrar -, a crítica de Foucault, em seu seminário, visa principalmente ao marxismo e aos marxistas, isto é, ela tem algo de específico das disputas teóricas francesas, daí o filósofo lançar mão dessa percepção mais ampla de poder. Para ele, a base econômica não determina as práticas e os discursos de controle, ela se vale deles, se articula a eles, para se propagar. Assim, ideologia, para Foucault, não é falsa consciência; ideologia é, antes assim como em Althusser -, o que sustenta qualquer regime de verdade, porque não há conhecimento puro (toda a primeira parte da conferência é usada para defender essa ideia, a partir de Nietzsche). Em outras palavras, não há teoria sem ideologia. É justamente o que Ana Cristina enfatiza em seu texto do Opinião para criticar Costa Lima.

De sua parte, ele propõe a existência de um inconsciente da estrutura, que determina as relações de linguagem e que deve ser o objeto de pesquisa do analista. Ou seja, persiste um objeto a ser dissecado, e que não se confunde com a ideologia, pois diz de uma estrutura mais profunda. Essa ideia - que, como se verá, é desenvolvida em seu livro de 1973, Estruturalismo e teoria da literatura -, de modo implícito em sua resposta, no texto intitulado "O bloco do eu sozinho", publicado no número seguinte do Opinião. Detalhe importante: Ana Cristina César não é sequer nomeada. Costa Lima se dirige a Cacaso, Carlos Nelson Coutinho e Leandro Konder, colegas professores, portanto, e, curiosamente, às falas dos alunos que Ana Cristina reproduz em seu texto. Trata-se, no geral, de uma conversa entre pares e entre homens. A atitude visa a elucidar pontos do seu pensamento que os colegas parecem não ter compreendido. Corroborando uma prática comum entre teóricos, intelectuais e escritores, de fugir dos rótulos, Costa Lima (1975b) inicia afirmando que não se vê como um estruturalista, mas como alguém que reflete a partir do estruturalismo. ${ }^{12}$ E pensa que, ao contrário do que se escreve sobre

\footnotetext{
" "Se nós entendemos poder como uma coisa única, convertemos poder em fetiche. Teríamos que analisar, antes, as condições negativas e positivas do poder, pois, se eu não faço essa distinção, estaria em vias de estabelecer simplesmente uma base anarquista ou, em uma versão mais contemporânea, uma versão acadêmica, erudita, de um pensamento hippie" (FOUCAULT, 1994, pp. 641-642).

${ }_{12}$ De acordo com Gisèle Sapiro e Lucile Dumont (2016, p. 125), "essas etiquetas acabam sendo na maioria das vezes limitantes, quando os indivíduos querem afirmar a sua autoridade (no sentido de authorship), já que a singularidade é uma condição de acesso à consagração, tanto no campo literário quanto no acadêmico. Assim, a partir de 1968, Foucault nega publicamente seu pertencimento à corrente estruturalista”.
}

Remate de Males, Campinas-SP, v.40, n.2, pp. 697-722, jul./dez. 2020 - 708 
ele, sua formalização não é necessariamente "radical", formaliza para que as deduções possam ser acompanhadas sem autos de fé, isto é, para que se evidencie algo como uma prova científica. Além disso, não concorda que literatura seja ideologia, embora pense que ela possa se basear em proposições ideológicas. Mas o principal do argumento está na sua discordância tanto da noção de linguagem trazida por Coutinho - como se ela fosse um suporte dos conteúdos sociais, o que exclui a carga semântica -, quanto da leitura de Leandro Konder, parceiro teórico de Coutinho, que, ao interpretar um poema de Drummond, vê o que quer ver ou o que o poeta quer que ele veja, isto é, uma representação da realidade, e não a estrutura, isto é, o inconsciente do texto. No caso, o artigo é, igualmente, uma tentativa de conversa franca com os adversários, apesar das ironias aqui e ali, mas com pontos de concordância. Por exemplo, Costa Lima também acha que há um fetiche em torno da teoria e que esta não deve vir sem o texto literário, para não ser inócua. Vê, como Merquior, que há populismo na abertura de vagas na universidade para pessoas despreparadas, o que gera, segundo ele, o "anafalbetismo ilustrado de mestres e alunos" (LIMA, 1975b, p. 23).

Por fim, importa dizer que Costa Lima não responde à questão de a teoria mesma se vincular a uma prática institucional e ideológica. Talvez porque discutir em um artigo de jornal algo que subjaz à construção da sua obra e de toda uma propedêutica, signifique, naquele momento, ir na contramão de uma missão mais alta, o embate teórico que, na sua visão, é o que pode impulsionar os estudos literários no Brasil, dando mais autonomia, seja ao discurso crítico, seja aos que se dedicam a estudá-lo. Pois, para ele, opondo-se ao que pensa Cacaso e Ana Cristina César (via Foucault), o direito de teorizar sobre a literatura precisa ainda ser conquistado, principalmente na universidade brasileira - que é de onde, e para onde, ele fala quase que exclusivamente. E é justamente aí, nesse âmbito, que, como se verá, ancoram-se as suas ideias em torno não apenas da teoria, mas do que ele chama de sistema intelectual brasileiro.

Como se viu, alguns intelectuais do período julgaram as teorias estruturalistas como uma moda teórica importada da França, uma planta exógena sem nenhum interesse para a cultura literária do Brasil, muitas vezes usadas por oportunistas que queriam ingressar, a fórceps, na carreira acadêmica. Mais ainda, em um contexto de ditadura militar sustentado 
pelo governo estadunidense, em que se discutia a dependência econômica e cultural, o pensamento estruturalista, ao abolir a diacronia em favor da sincronia e o contexto em favor do texto, parecia-lhes apolítico e alienado, pois, segundo eles, não permitia compreender a história social do Brasil, sendo a incompreensão ou o esquecimento desta o foco da ditadura militar. Outra crítica era a de que os adeptos dessas teorias não eram capazes de politizá-las, isto é, relacioná-las às próprias políticas da instituição universitária.

Porém, se observadas a partir das dinâmicas do campo literário, as teorias estruturalistas não só ameaçavam poetas e intelectuais de fora da universidade como, também, enfrentavam concepções críticas próximas do materialismo dialético e da fenomenologia -, já consagradas, respectivamente, nos cursos de graduação e pós-graduação em teoria literária e literatura brasileira da Universidade de São Paulo e da Universidade Federal do Rio de Janeiro. Ou seja, elas forçavam barreiras teóricas que foram sendo construídas desde a década de 1930, quando da fundação das primeiras universidades no Brasil.

Assim, concordando em boa medida com um texto-depoimento de Eneida Maria de Souza (1998), intitulado "Os livros de cabeceira da crítica”, penso que essas teorias tiveram de fato um papel decisivo no processo de diferenciação dos estudos literários no Brasil. Como afirma essa autora, elas contribuíram para o desenvolvimento de uma cultura teórica no campo literário, valorizaram formas culturais marginais (como a música popular) e trouxeram novas possibilidades para a leitura tanto de obras canônicas quanto de obras contemporâneas.

Além do mais, diria que, mesmo no início dos anos 1970, os primeiros pesquisadores brasileiros que se consagraram às teorias estruturalistas não estavam de modo algum distantes da realidade local, bem ao contrário. Minha hipótese é a de que esses scholars se aproximaram, cada um à sua maneira, de uma das questões importantes do momento, a saber, a da dependência cultural, ao mesmo tempo em que, a partir dela, se posicionaram no espaço acadêmico. ${ }^{13}$ Mesmo se reportando ao

\footnotetext{
13 A contribuição de Sant'Anna, na PUC-Rio, é sobretudo como professor, orientador e mediador cultural. De 1970 a 1978, orienta 13 dissertações de mestrado. Ainda, é ele quem convida Silviano Santiago para ingressar na PUC-Rio, segundo depoimento do próprio Santiago. Sobre a vinda de Foucault a essa instituição, em 1973, especula-se que Sant’Anna fez o convite. Não tão significativa no período, a obra crítica de Affonso Romano de Sant'Anna enfatiza a etapa analítica, de desmontagem do texto, como se pode observar em seu livro Análise estrutural de romances brasileiros, publicado no início dos
} 
que se passava fora dela, foi a partir da universidade que eles pensaram sobre o problema da dependência. Dito de outro modo, se, por um lado, eles refletiram sobre como confrontar essa dependência, ou, ainda, se se perguntaram como o estudo teórico poderia conduzir à independência cultural e científica, por outro, eles visaram ao combate das dependências na própriaárea, istoé, deum sistema intelectual em tornodepersonalidades e ideias estabelecidas que, apesar de certa tradição e consistência, no limite, atravancava a democratização dos estudos literários.

Em 1973, Silviano Santiago publica o texto "The Latin-American Literature: The Space in-between", mais tarde, republicado como "O entre-lugar do discurso latino-americano". ${ }^{44}$ Em síntese, nesse texto, Santiago (1978) critica uma teoria literária com base nas fontes e influências e, da mesma forma, no que ele chama de pseudomarxismo, na medida em que este torna evidente a leitura do texto literário, que deriva automaticamente de uma base econômica. Como saída, Santiago propõe aos artistas e intelectuais do Terceiro Mundo - categoria da época, que ele utiliza - a desconfiança em relação aos poderes do colonizador. A estratégia, de base modernista-oswaldiana, antropofágica, pensada a partir de uma lógica que, alguns anos depois viria se chamar pós-colonial, é a de desafiar o colonizador, mas após ter interiorizado a sua estratégia. A resposta cultural vem, assim, na forma de uma obra ou texto crítico que incorpora a cultura dita superior, mas que, ao mesmo tempo, a questiona, uma obra que, ao invés da obediência a um modelo, propõe a diferença.

Há um diálogo tenso entre essa proposta e a de Roberto Schwarz, que se pode ler em "As ideias fora do lugar" - introdução da sua tese de doutorado, de 1976 -, publicada com o mesmo título em $1973^{15}$ (ou seja, no mesmo ano da publicação do artigo de Santiago em inglês), e,

anos 1970, em que ele busca, por meio de um repertório crítico estrangeiro, mormente francês e estruturalista, evidenciar a validade e a universalidade do método para a análise de quaisquer objetos literários. Sem necessariamente desvendar as particularidades sociais brasileiras, que estariam, em uma perspectiva uspiana, internalizadas nos textos, a literatura do Brasil não figura, assim, nem como dependente, nem como revolucionária, no plano social, mas, simplesmente, como literatura, isto é, como uma parte legítima da literatura do Ocidente. Ela não é um ramo da literatura portuguesa e europeia, como defende Candido na sua Formação da literatura brasileira. Em Sant'Anna, o analista pode aplicar, como ferramentas de análise, os ensinamentos dos estruturalistas e demonstrar que eles funcionam, sem maiores problemas, no estudo do texto local.

${ }^{14} \mathrm{O}$ texto foi escrito originalmente em francês, com o título "L'entre-lieu du discours latino-américain”, para uma palestra em 1971, na Universidade de Montreal.

${ }^{15}$ No número 3 da revista Estudos Cebrap.

Remate de Males, Campinas-SP, v.40, n.2, pp. 697-722, jul./dez. 2020 - 711 
em 1977, no livro Ao vencedor as batatas. Se a solução de Santiago para superar a dependência cultural é, sobretudo, questão de mudança de paradigma crítico, de substituição dos pressupostos, de uma visada crítica do colonialismo, a de Schwarz (1981) exige, entretanto, um longo e difícil trajeto. Seu duplo pressuposto é o de que 1) a dependência resulta da lógica combinada e desigual do capitalismo, e não é por um passe de mágica que se vai superá-la, e o de que 2) as formas literárias estão intimamente ligadas ao processo social e aos modos de produção e, portanto, reproduzem aquela dependência, sendo a superação o resultado de um trabalho crítico - de dentro e de fora - sobre as formas tradicionais, como no caso exemplar de Machado de Assis. Com base nesses pressupostos, o próprio modelo crítico de Schwarz demanda, de um lado, o aproveitamento das conquistas da tradição - tal a releitura de Alencar por Machado, proposta em sua tese de doutorado - e, de outro, a seleção de teorias estrangeiras similares, com as quais se dialoga. ${ }^{16}$ Para Santiago (1978), pouco importa a duração do processo de libertação/superação do jugo do colonizador/ fonte, pois não é necessariamente a acumulação que leva à independência, mas a tenacidade, a inteligência, a criatividade e o acaso, que acabam por ter um papel decisivo nas formações culturais. Assim, sua visão de história é construída a partir de um ponto de vista pós-estruturalista, feita mais de rupturas do que de continuidades. E é justamente por não ter um compromisso com a memória de um passado pesando sobre as costas que o intelectual terceiro-mundista, na visão do crítico, pode, depois de ter deglutido o inimigo, ser ousado e superá-lo.

O que une os dois críticos é a aposta em uma vantagem da periferia, já que, para ambos, escritores e intelectuais vindos de países pobres e colonizados estariam desprovidos das ilusões (ou ideologias), seja as do capitalismo, seja as do processo de colonização. O que os diferencia é que, mesmo que os títulos dos artigos de Schwarz e Santiago remetam ao espaço - "lugar" e "entre-lugar" - eles discutem, principalmente, as temporalidades para a superação da dependência econômica e cultural, que, para eles, são diametralmente opostas. Talvez, as diferentes concepções sobre o tempo de superação da dependência cultural se expliquem, em parte, pelas posições de cada um deles no subcampo da crítica: um é herdeiro de Antonio Candido e do Grupo do Capital, ou seja, mesmo tendo feito mestrado e doutorado no exterior, está atrelado a uma

\footnotetext{
${ }^{16}$ Alguns autores europeus que inspiram a teoria também conhecida como literatura e sociedade são Karl Marx, Georg Lukács, Theodor Adorno, Eric Auerbach.
} 
filiação a uma tradição intelectual de longo termo, já assentada em uma das universidades mais antigas do país; o outro é um recém-chegado, “estrangeiro", de Minas Gerais, do Canadá, dos Estados Unidos, da França, que, sem todos os trunfos, deve, por esforço próprio, romper com aquela tradição e se situar no espaço acadêmico, por isso sua assertiva de que, da mesma forma, a cultura da periferia possa prescindir da longa duração para se superar. Não obstante, ela não pode prescindir da leitura e, digamos, da voracidade da leitura. De acordo com Santiago (1978, p. 37), "o escritor [e por extensão, o intelectual] latino-americano é o devorador de livros de que os contos de Borges nos falam com insistência. Lê o tempo todo e publica de vez em quando", leitura esta movida pela "práxis da escritura" (p. 36).

À mesma época, Luiz Costa Lima, um recém-chegado ao centro intelectual do país, à época, vindo de Recife e instalado no Rio de Janeiro, com a polícia política em seu encalço por conta do AI-1, também reflete sobre o problema da dependência cultural do Brasil, e por caminhos que, de forma similar, apontam, simultaneamente, para o exterior e para o interior do universo acadêmico. no entanto, se, como Santiago, Costa Lima rejeita a busca das fontes e influências, como Schwarz, ele aposta na acumulação, mas, no caso, teórica e científica. Ele não descarta a erudição, isto é, a referência aos pensadores clássicos, só que não abre mão da bibliografia up to date. Ainda, não pensa que a formação teórica passe por uma crítica baseada na lógica econômica do capitalismo como sistema-mundo ou por uma escola de pensamento que promova a articulação entre forma literária e processo social. Seu pressuposto é o de que a dependência resulta não necessariamente de um imperialismo teórico, mas de limitações impostas, sobretudo internamente, por elites desejosas de conservar o seu poder. São elas fruto de um sistema patriarcal ainda vigente, cuja base de transmissão da cultura é a oralidade, e devem ser superadas.

A principal contribuição de Costa Lima, no início dos anos 1970, é uma obra de mais de 400 páginas, que resulta de sua tese de doutorado, intitulada Estruturalismo e teoria da literatura, cujo objetivo é o de conceber uma teoria estrutural do discurso literário. Trata-se de obra densa, construída a partir de longos comentários sobre autores que pensaram sobre a linguagem, desde Platão, passando por Hegel e Kant, até os estruturalistas. A recepção favorável das teorias estruturalistas atravessa o livro, desde a crítica do logos, em Derrida, até a visão da história 
como ruptura, em Foucault. Mas são Lévi-Strauss e Lacan os autores mais utilizados. Mesmo vindo de disciplinas não literárias, são eles que dão o embasamento ao seu estudo. Assim, ele toma distância dos predecessores, isto é, das teorias estéticas, da estilística e do formalismo russo, os quais ele concebe como prisioneiros da linguagem literária; mesmo a ideia formalista de "desvio" não difere da estilística e da estética, já que também pensa o poético como ato de impressão que serve para intensificar a experiência do receptor, retomando, assim, a ideia romântico-simbolista de poesia, sem que se saia do círculo encantatório dos efeitos verbais. Para dele escapar, é necessário, segundo a proposta do autor, uma teoria que se separe do literário em si. É, primeiramente, em Kant que Costa Lima encontra uma via, uma abertura do processo de análise em direção ao conhecimento, em que a teoria confronta um outro corpo teórico, a partir do qual é possível medir a validade de suas hipóteses. Para ele, é fundamental construir um corpo teórico, senão o que se obtém é sempre a repetição do que já se encontra na superfície das obras, ou seja, do estilo. Ele explica seu modelo desta forma: "a análise literária tem por lugar o ponto de cruzamento formado por uma atitude epistemológica, o estruturalismo, e uma ciência, a psicanálise. Tal cruzamento determina uma situação antropológica” (LIMA, 1974, p. 217), isto é, uma situação não antropocêntrica, em que o texto se torne o Outro. Ainda, segundo Costa Lima, "para uma análise de cunho estrutural o verdadeiro problema estará na descoberta da lógica do significante, situada aquém do estilo" (p. 218). Escreve o autor, algumas páginas adiante, que

[...] não há [...] cultura fora da sociedade. É então a sociedade que motiva a instituição [da proibição] do incesto, que serve de baliza para a feitura dos sistemas de aliança. Por outro lado, e apesar de sua importância capital, os homens, indistinção feita desta ou daquela sociedade, o empregam sem terem consciência de seu significado (LIMA, 1974, p. 237).

Contra uma compreensão da obra literária como resultado de uma base ou infraestrutura econômica determinante ou de uma consciência que está acima delas, Costa Lima se vale dos dois pensadores cardeais do estruturalismo ${ }^{17}$ para apreender a lógica interna do discurso literário. Ainda, se o esteta e o hermeneuta se preocupam com a enunciação e o

\footnotetext{
${ }^{17}$ É como Frédérique Matonti (2019[2005]) se refere a Lacan e Lévi-Strauss em seu texto "La politisation du structuralisme. Une crise dans la théorie”. De sua parte, embora também se refira a Lévi-Strauss, Silviano Santiago se vale principalmente dos novos, Derrida e Foucault, para formular sua teoria sobre o entre-lugar.
} 
enunciado, o teórico da literatura visa a construir um aparato no sentido de descobrir as oposições que formam um sistema discursivo. Segundo Costa Lima (1974, p. 300), a abordagem de Lévi-Strauss permite "romper com o privilégio - verdadeiro obstáculo para o conhecimento da poesia, embora benéfico aos poetas - do discurso literário, que o deixa afastado da ciência e o aproxima das frases de efeito". Então, para a concepção estrutural, a polissemia forma tão somente o nível superficial de um poema, e as intenções declaradas dos escritores não contam. O que conta é o conjunto sistêmico, no nível do paradigma: "a problemática sistêmica procura revelar os invariantes do texto, ou seja, os traços mínimos que, articulados, darão o sentido" (LIMA, 1974, p. 404). Segundo o autor, em uma referência à psicanálise lacaniana e à antropologia lévy-straussiana, "tratar do discurso é, portanto, chegar ao inconsciente, na tentativa de descobrir a lógica do significante, o plano do sentido, que sempre escapa entre as interpretações da significação" (LIMA, 1974, p. 461).

Em uma carta de dezembro de 1973 - portanto, no mesmo ano da publicação da tese -, Costa Lima, que dirigia, no Rio, um grupo de estudos sobre a obra de Lévi-Strauss, pede ao antropólogo alguns esclarecimentos. Entre outras coisas, ele pergunta 1) se entre Antropologia estrutural e a série Mitologias sua concepção de inconsciente não mudou, 2) como se poderia adaptar a análise dos mitos, constituída a partir de um vasto corpus de variantes, à análise literária, que é mais autossuficiente, 3) como ele, Lévi-Strauss, vê a possibilidade de articulação entre seu método e a contribuição original da releitura de Freud feita por Lacan e seus discípulos (entre eles, dois dos citados na tese são Lucy Irigaray e aquele que se tornaria o herdeiro de Lacan, Jacques-Alain Miller), ou 4) se, ao contrário, há diferenças absolutas entre a concepção de inconsciente da psicanálise e da que aparece no final de $O$ homem nu. ${ }^{18}$

Não são conhecidas as respostas de Lévi-Strauss, já que, à diferença da maior parte de sua correspondência com a América Latina, ele não deixou uma cópia para si das cartas que enviou a Costa Lima. ${ }^{19}$ Mesmo assim, as questões, como foram feitas, permitem perceber o engajamento do autor na apreensão dos conceitos de Lévi-Strauss, além do conhecimento do campo intelectual e psicanalítico francês. Também, ele quer evitar

${ }_{18}$ Collège de France. Laboratoire d'Anthropologie Sociale. Référence de la lettre: FLAS.F.S5.02.01 (Lettre de Luiz Costa Lima à Claude Lévi-Strauss).

19 Em entrevista a mim concedida, Costa Lima afirmou que não sabia do paradeiro das cartas de Lévi-Strauss. 
a mescla arbitrária e articular adequadamente as duas disciplinas não literárias a serem utilizadas na sua leitura literária, o que aponta, outra vez, para o desejo de rigor científico no trabalho intelectual. Nessa mesma carta, antes mesmo de fazer as perguntas, ele escreve que sua intenção é, a partir da resposta de Lévi-Strauss, diminuir os equívocos constantes (e inevitáveis) na aplicação do estruturalismo à crítica literária.

O esforço de Costa Lima é, assim, o de contribuir para a evolução dos estudos literários, pensando a teoria literária mais próxima da filosofia, da psicanálise e da antropologia do que da própria literatura. É como se, para que esta fosse lida adequadamente, o analista, como um cientista, necessitasse tomar distância dela. Nesse sentido, não é nada aleatória, no rol de referências possíveis do estruturalismo, a opção por Lévi-Strauss (e não, por exemplo, por Roland Barthes) como possível interlocutor, cuja obra, consagrada na França e no Brasil, passa a fazer parte mais do campo científico do que do literário. Ao mesmo tempo, para Costa Lima, e como se pode notar na correspondência com o antropólogo francês, trata-se de construir uma teoria, por isso a sua crítica frequente àqueles colegas estruturalistas que, simplesmente, aplicam os conceitos vindos de fora. Em depoimento recente, ele afirma que

\section{[...] meu enfado com um tipo de "estruturalismo" que vigorou, por um curto momento, por influência de um hoje esquecido Greimas, na crítica literária nacional, resultava de generalizações dessa ordem. Seu quadro de actantes podia ser "utilizado", passado de uma obra para a outra, manipulável como esqueminha que certos professores e muitos alunos adoram adotar (LIMA apud BASTOS, 2010, p. 114).}

Em grande medida, as posições de Costa Lima, em seu livro de 1973, condizem com a transformação e expansão do sistema universitário brasileiro, que se torna mais profissional, mais especializado, mais técnico-científico, e que vai ocupando, pouco a pouco, o centro do campo intelectual. Daí, como se viu na primeira parte deste artigo, o autor ser alvo dos grupos residuais (poetas, diplomatas, acadêmicos da ABL). Ainda, no âmbito desse sistema, o autor confronta, além de seus colegas da PUC-Rio (mais especificamente Affonso Romano de Sant'Anna), tanto os críticos tidos como impressionistas da UFRJ (Afrânio Coutinho entre eles) quanto os colegas da Universidade de São Paulo, com os quais ele mantém uma relação distanciada, crítica, e, ao mesmo tempo, respeitosa. Como é sabido, foi Antonio Candido quem aceitou orientar seu doutorado, que o acolheu em São Paulo quando estava sendo perseguido pela polícia 
da ditadura. Mas é bem possível que Candido tenha refutado as ideias presentes na tese (o que é insinuado por Costa Lima nos agradecimentos do livro), ${ }^{20}$ sobretudo porque elas questionavam muitas das chaves de leitura do orientador, entre elas, o corpo a corpo com o texto literário, a relação entre literatura e sociedade, a atenção ao estilo e a aspectos biográficos dos autores e, principalmente, a ausência de discussão teórica que, mesmo compensada por um gosto refinado e uma erudição rara, repousa sobretudo em escolhas individuais, possíveis, sobretudo, a partir da herança de um alto capital cultural. A opção de Costa Lima pela teoria - e pela ciência - é, também, em última análise, um contraponto à leitura literária segundo a qual esse capital é indispensável.

Em uma passagem de seu livro, há um trecho em que o autor sugere essa relação entre leitura, autoridade e erudição, o que demonstra que a questão do poder e, mais especificamente, do poder institucional, não está ausente de sua discussão teórica. Segundo ele,

\begin{abstract}
A estilística representa a leitura hermenêutica plena - restitui o "saber" que o sujeito criador investiu no objeto - que trabalha pela constituição de um texto segundo, "compreensivo", montado sobre o texto primeiro, glosa sofisticada que "interpreta" o que o autor quis dizer, passando do explícito ao mais explícito. A hermenêutica plena da estilística não se dispõe ao lado do formalismo, pois não necessita abandonar a semântica, confundida com o que o autor "quis dizer"; apenas, em troca, não consegue constituí-la cientificamente, pois se contenta com um jogo especular: as significações consciente/intuitivamente introjetadas pelo criador se espelham, com maior nitidez, nas significações interpretadas pelo analista. Segundo a leitura hermenêutica, o texto é pleno por sua fala. Haverá apenas zonas de sombra na fala, por efeito seja das limitações humanas do criador, seja por algum motivo de esconde-esconde que teve de adotar. $\mathrm{O}$ hermeneuta é o mestre das sombras (LIMA, 1974, pp. 163-164).
\end{abstract}

Critica-se, aqui, a leitura que realça, além das qualidades do autor literário, a própria autoria/autoridade do hermeneuta, que produz uma "glosa sofisticada" e que, espelho daquele, é quem possui as chaves do mistério do texto. E, se ele é o mestre, supõe-se que o passo além - a releitura do mesmo texto, do mesmo autor, de um mesmo conjunto de obras - só será possível depois de se ter transcorrido o seu percurso, prática que não pode prescindir da revisão da fortuna crítica, que tem no seu cerne a ideia de uma formação via acumulação das leituras dos primeiros intérpretes no sentido de superá-las e, com isso, ao mesmo tempo,

${ }^{20}$ Nos Agradecimentos ele escreve: "Ao professor Antônio Cândido [sic] de Mello e Sousa [sic], que aceitou orientar uma tese com que poderia não concordar" (LIMA, 1973, p. 5). 
render-lhes a devida homenagem. Ritual de leitura que valoriza tanto a personalidade do(s) intérprete(s) quanto o texto que se lê e que possui paralelo com o que ocorre em âmbito institucional. Porque, no momento em que Costa Lima publica sua tese, o ingresso na carreira universitária em uma universidade tradicional como a USP depende não só de se ter um doutorado, como afirma Roberto Schwarz em seus "19 princípios...", mas, também, da fidelidade aos passos do orientador de tese, uma espécie de mestre das sombras, pelo qual se precisa esperar (mais uma vez a questão do tempo), ${ }^{21}$ até que se consiga a permanência definitiva na instituição. ${ }^{22}$

\footnotetext{
${ }^{21}$ Com efeito, segundo Pierre Bourdieu (2013), no modelo da universidade francesa antes das mudanças de final de 1960, que encontra paralelos nas universidades brasileiras mais endógenas do mesmo período, o orientador em geral controla o acesso à única posição possível, a de professor de uma faculdade. De acordo com o sociólogo, "esse poder sobre os mecanismos de reprodução, e portanto, sobre o futuro do corpo, que encontra sua plenitude nas faculdades de medicina, repousa sobre o controle, pela cooptação, do acesso ao corpo universitário, sobre as relações de proteção e dependência duráveis entre o orientador e seus clientes, e enfim sobre o controle das posições institucionais de poder, bancas de concurso de admissão, Comitê consultivo, conselhos de faculdade, ou mesmo comissões de reforma. Mas o melhor fiador da ordem acadêmica, inseparavelmente social e científica, reside sem dúvida nos mecanismos complexos que fazem com que o avanço em direção ao topo das instituições dominantes temporalmente vá de par com uma progressão na iniciação acadêmica, marcada, no caso das faculdades de medicina, pela sucessão dos concursos (que, como nota um observador, empurra para bem tarde a verdadeira iniciação aos métodos científicos do laboratório), ou, nas faculdades de letras, pela longa espera da tese de doutorado, isto é, nos dois casos, por um esforço prolongado das disposições que foram reconhecidas pelos procedimentos primitivos de cooptação e que não se inclinavam muito à ruptura herética com os saberes e os poderes sabiamente entrelaçados da ortodoxia acadêmica" (pp. 142-143). Ressalte-se, na passagem, a relação entre poder e saber, entre dependência e temporalidade lenta.

${ }^{22}$ No período de 1970 a 1982, Antonio Candido orienta 35 pessoas. Dessas, algumas fazem mestrado e doutorado, outras apenas doutorado, no sistema antigo (sem disciplinas) e no sistema novo (da Capes). Dos 35 orientandos, 20 são mulheres e 15 são homens, dado que aponta uma leve variação de gênero. Desse grupo, 21 pessoas se tornam docentes na própria USP (13) ou nas outras universidades do sistema paulista (8), na Universidade de Campinas (Unicamp) e na Universidade Estadual Paulista (Unesp), sendo que, na primeira, Candido é o responsável por fundar o Instituto de Estudos da Linguagem. Comparando com a PUC-Rio, do grupo orientado por Affonso Romano de Sant'Anna, são 9 mulheres e 4 homens; dos orientandos de Costa Lima, são 10 mulheres e um homem; e dos de Silviano Santiago, são 8 mulheres e três homens, o que dá um total de 27 mulheres e 8 homens, orientados pelos três professores "estruturalistas" da PUC-Rio. Esse contingente ocupará vagas em outras universidades, seja no estado do Rio de Janeiro, nas universidades novas que surgiam - Universidade Federal Fluminense (UFF), Universidade da Cidade do Rio de Janeiro (UniRio) e Universidade do Estado do Rio de Janeiro (UERJ) -, seja em outros estados do Brasil, Universidade Federal de Minas Gerais (UFMG), Universidade Federal do Ceará (UFC), Universidade Federal da Bahia (UFBA), Universidade Federal do Rio Grande do Norte (UFRN), Universidade Federal do Paraná (UFPR). São raros os casos
} 
Em artigo de 1978, retomado em 1981, Costa Lima também se debruça sobre essas questões institucionais, sem as mencionar diretamente, indicando, contudo, a mesma relação e frisando o modo como elas aparecem nas práticas de leitura. Para ele,

\begin{abstract}
[...] o fato extremamente grave quanto ao caráter do sistema intelectual brasileiro está em que o autoritarismo dos regimes autocráticos se harmoniza com a tradição acrítica de nosso pensamento, com a sua falta de estímulo ante qualquer indagação teórica, com o seu medo de ousar de modo consequente. Desta forma, o autocratismo político estimula, seja inconscientemente, mesmo entre os seus adversários, o receio do pensamento reflexivo, a prática intuicionista e o temor de que a indagação teórica não passe de uma modalidade do escapismo. Assim a velha matriz se realimenta e passa a viver mesmo entre aqueles que ideologicamente se opõem às formas econômicas e políticas que lhe corresponderam. $\mathrm{O}$ pior do autoritarismo não está em que seus agentes sejam autoritários, mas que seus adversários, pelos entraves à discussão crítica, tendam para a mesma prática autoritária. E, do ponto de vista do sistema intelectual, o pior do autoritarismo é que ele acostuma a intelligentsia ao pensamento impositivo, que não precisa demonstrar, pois lhe basta apontar, mostrar com o dedo "a verdade" (LIMA, 1981, pp. 14-15).
\end{abstract}

Linhas antes, ele se referia à USP como essa adversária da cultura auditiva, forma cultural do que chama, nessa passagem, de autocratismo político: "a USP passou a fornecer levas de nomes que, no estudo da literatura, na sociologia, na história e na filosofia, sacudiram a tradição auditiva da cultura brasileira" (LIMA, 1981, p. 14). Ao conectar esse trecho à sequência do argumento, fica evidente o ethos ambíguo dessa instituição que, para Costa Lima, também sofreria com o revigorar das velhas matrizes do pensamento brasileiro. Por isso, em entrevista recente sobre Estruturalismo e teoria literária, a Roberto Acízelo de Souza, o autor, que discorria sobre o risco de escrever uma tese sobre o estruturalismo em uma universidade "em que o tema era visto como algo politicamente suspeito” (LIMA apud BASTOS, 2010, p. 88), aponta, entre parênteses, mas, paradoxalmente, de modo bem direto, essa ambiguidade: "(Se devemos à USP haver sido o foco de resistência intelectual ao negror da ditadura, devemos também reconhecer que ela era tão autoritária como as

de mestres formados na PUC-Rio que ingressarão tanto nos sistemas universitários mais antigos, ou seja, mais tradicionais e mais legítimos (como a USP e a UFRJ), quanto na própria PUC-Rio. O interessante, para análise futura, é que tanto Silviano quanto Costa Lima terão, depois dos primeiros anos PUC-Rio, duplo vínculo, respectivamente, com a UFF e a UERJ. Os dados foram retirados da plataforma eletrônica do acervo da biblioteca da Universidade de São Paulo (<www.dedalus.usp.br $>$ ) e do acervo da PUC-Rio (<http:// www.dbd.puc-rio.br/sitenovo/\#aviso>).

Remate de Males, Campinas-SP, v.40, n.2, pp. 697-722, jul./dez. 2020 - 719 
nossas chamadas elites costumam ser)" (LIMA apud BASTOS, 2010, p. 88). Se, por um lado, na sua visão da USP, há, ali, ruptura com o status quo autoritário, há também permanência, donde o veto à teoria (ou, talvez, à sua teoria), o que, de acordo com ele, emperraria a discussão em torno dos modos de ler literatura e crítica literária no Brasil.

Portanto, para Costa Lima, em 1973, as relações de dependência na sociedade brasileira - mais especificamente em nosso sistema cultural não têm a ver somente com a posição desta no sistema-mundo capitalista (Schwarz), nem com as relações pós-coloniais (Santiago), mas com um sistema de dominação patrimonialista que impede o surgimento de outras vozes nos âmbitos social, cultural e, especificamente, institucional. Contra essa estabilidade de corte elitista, requerida por Merquior em sua crítica ao estruturalismo, a teorização não apenas se torna passível de ser testada/refutada - cientificamente, diga-se de passagem -, como, também, a discussão proposta por ela pode emular o próprio exercício intelectual, livrando o scholar/pesquisador da dependência, isto é, tanto da mera aplicação de ferramentas quanto do culto da personalidade. No fundo, porém, o que se viu, com a forte institucionalização dos estudos literários iniciada nos anos 1970, foi que a autoridade do professor erudito migrou menos para o exercício teórico do que para os modelos teóricos aplicáveis, que se disseminaram e se multiplicaram nas últimas décadas.

No final da década de 1970, Costa Lima já se encontrava em outra empreitada, agora em torno das questões do controle do imaginário e do veto à ficção. A pergunta que fica é: Até que ponto as reflexões em torno da dependência (e do patrimonialismo) e da sua superação - que busquei ressaltar neste ensaio, por meio da leitura do livro teórico de 1973 - não estão na origem do que veio depois? Em outras palavras, até que ponto as críticas ao controle e à imitatio não consistem, também, em críticas a outras formas de censura e, mais do que isso, aos enquadramentos da ficção por uma certa leitura de Brasil e da função da crítica e da literatura? Matéria para outro ensaio, tal pergunta sugere um aspecto já detectado aqui, a saber, o da indissociabilidade entre percurso intelectual, institucionalização, teoria e política (lato sensu) nos estudos literários brasileiros, mesmo quando se tem como meta romper - caso da teoria da literatura de Costa Lima - com a heteronomia do discurso teórico. 


\section{REFERÊNCIAS}

ANDRADE, Carlos Drummond de. Exorcismo. Jornal do Brasil, 12 abril de 1975, p. 5.

BASTOS, Dau (Org.). Luiz Costa Lima: uma obra em questão. Rio de Janeiro: Garamond, 2010.

BOURDIEU, Pierre. Homo academicus. Florianópolis: Ed. da UFSC, 2013.

BRITO, Antonio Carlos de. Bota na conta do Galileu, se ele não pagar nem eu. Opinião, 28 nov. 1975, p. 19.

CÉSAR, Ana Cristina. Os professores contra a parede. Opinião, 12 de dezembro de 1975, p. 20.

COUTINHO, Carlos Nelson. Há alguma teoria com medo da prática? Opinião, 28 de novembro de 1975, p. 19.

CUNHA, Luiz Antônio. A universidade reformanda: o golpe de 1964 e a modernização do ensino superior. Rio de Janeiro: Francisco Alves, 1988.

FOREST, Philippe. Histoire de Tel Quel. Paris: Seuil, 1995.

FOUCAULT, Michel. Dits et écrits, 1954-1988, tome II 1970-1975. Paris: Gallimard, 1994.

IVO, Ledo. A morte da literatura brasileira. O Globo, 23 de junho de 1975, p. 37.

LIMA, Alceu Amoroso. Revolução, reação ou reforma. Rio de Janeiro: Tempo Brasileiro, 1964 .

LIMA, Luiz Costa. Estruturalismo e teoria da literatura. Petrópolis: Vozes, 1973.

LIMA, Luiz Costa. Quem tem medo da teoria. Opinião, 21 de novembro de 1975a, p. 24.

LIMA, Luiz Costa. O bloco do eu sozinho. Opinião, 28 de dezembro de 1975b, p. 23.

LIMA, Luiz Costa. Dispersa demanda: ensaios sobre literatura e teoria. Rio de Janeiro: Francisco Alves, 1981.

LIMA, Rachel Esteves. A crítica literária na universidade brasileira. Tese (Doutorado em Estudos Literários) - Faculdade de Letras, UFMG, Belo Horizonte, 1997.

MATONTI, Frédérique. La politisation du structuralisme: une crise dans la théorie. Raisons Politiques, n. 18, 2005, pp. 49-71.

MERQUIOR, José Guilherme. O estruturalismo dos pobres. Jornal do Brasil, 27 de janeiro de 1974 , p. 5 . 
MORICONI, Italo. Ana Cristina César: o sangue de uma poeta. Rio de Janeiro: Relume-Dumará, 1996. (Perfis do Rio, 14)

SANTIAGO, Silviano. Uma literatura nos trópicos. São Paulo: Perspectiva, 1978.

SAPIRO, Gisèle; DUMONT, Lucile. La diffusion internationale du structuralisme: entre appropriation et rejet. In: BERT, J-F.; LAMY, J. (Dir.). Résonances des structuralismes. Paris: Editions des Archives Contemporaines, 2016, pp. 123-138.

SCHWARZ, Roberto. Ao vencedor as batatas: forma literária e processo social nos inícios do romance brasileiro. São Paulo: Duas Cidades, 1981.

SCHWARZ, Roberto. Sequências brasileiras. São Paulo: Companhia das Letras, 1999.

SOULIÉ, Charles (Dir.). Un mythe à détruire? Origines et destin du Centre Universitaire Expérimental de Vincennes. Paris: Presses Universitaires de Vincennes, 2012.

SOUZA, Eneida Maria de. Os livros de cabeceira da crítica. In: ANTELO, Raul et al. (Org.). Declínio da arte/Ascensão da cultura. Florianópolis: Letras Contemporâneas, 1998, pp. $15-24$.

Recebido: 9/12/2019

Aceito: 15/7/2020

Publicado: 4/12/2020

Remate de Males, Campinas-SP, v.40, n.2, pp. 697-722, jul./dez. 2020 - 722 